\title{
Antidiabetics and antihypertensive medications use in Morocco: A pharmacoepidemiological descriptive study

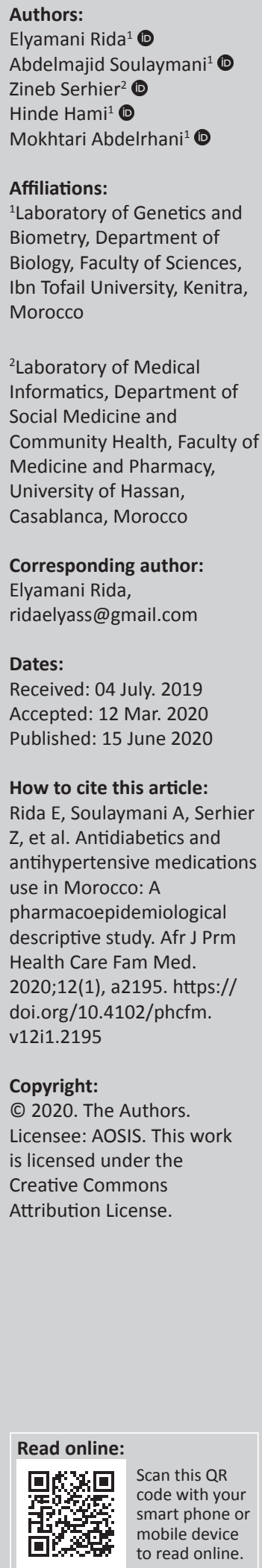

Background: In Morocco, and many other African countries, there is a paucity of antihypertensive and antidiabetics use amongst the general population.

Aim: To investigate the epidemiological profile of antihypertensive and antidiabetics use and analysis their adverse reactions.

Setting: This study was conducted in the prefecture of Figuig, Morocco.

Methods: A cross-sectional descriptive study. Data was collected using semi-structured questionnaire about their pharmacological treatment and presented using descriptive statistical analysis.

Results: Sample of 244 subjects, predominantly women $58.15 \%(p<0.03)$ composed of diabetic patients $56.96 \%(n=139)$ and hypertensive patients $43.03 \%(n=105)$. After adjustments, $60.24 \%$ of all patients were under monotherapy. The diabetics were being treated using the Biguanide class $(26.92 \%)$, insulin $(20.0 \%)$ and sulfonylureas $(10.0 \%)$ while hypertensive patients were treated by Calcium Channel Blockers (27.36\%), Angiotensin Converting Enzyme Inhibitors $(21.05 \%)$, Angiotensin T-Blockers $(16.84 \%)$, Diuretics $(7.36 \%)$ and $\beta$-adrenergic receptors blockers $(3.15 \%)$. In total, $23.00 \%$ of all subjects have experienced negative side-effects, mostly, reported $(90.38 \%)$ to health professionals and $23.52 \%$ of them have interrupted temporarily or try to change their treatment. Gastro-intestinal problems were the most adverse reactions reported $(11.11 \%)$ followed by headache, dizziness and tinnitus $(6.66 \%)$ and asthenia, feeling sick and feeling of faintness $(5.33 \%)$.

Conclusion: Managing diabetes and hypertension entails a lot of public challenges and requires more focus and interest, especially amongst the illiterate population in remote areas. Some of the suggested ways to help face the problem include the introduction of new innovative measures, systems of fellow-up and adverse reactions.

Keywords: pharmacoepidemiology; antidiabetics; antihypertensive; Morocco; pharmacovigilance; medication safety.

\section{Introduction}

Diabetes and hypertension remain the most common public health problems in the world and are the major risk factors for cardiovascular diseases that are the leading cause of death. ${ }^{1}$ Globally, both diseases affected nearly 2 billion people, with 1.4 billion hypertensive subjects and 425 million diabetic subjects, and accounted directly for 7.5 million and 1.6 million deaths respectively in 2017 (World Health Organization). The pharmacological treatment using antihypertensive and antidiabetics is core to any medical procedure for resolving these chronic diseases in any population, especially in developing countries where the availability of the pharmaceutical products remains a real challenge for governments in terms of both the technological innovation (generics penetration) and the economic burden. ${ }^{2}$ Daily use of these medications, and for long terms, is a complicated process affected by the psychological adjustment of subjects, their socioeconomic status and the mixture of compounds for treating the chronic conditions, regarding their effectiveness, their adverse reactions, their cost and their availability. To achieve positive therapeutic goals represented by positive clinical outcomes, and therefore prevent macrovascular and microvascular complications, subjects have to adhere to long-term guidelines and strategies for diets and pharmacological treatment following prescribed daily doses. ${ }^{3,4}$ Generally, for diabetes and hypertension, there are two major indications for changing the medication: a therapeutic failure and/or the appearance of serious adverse reactions or discomfort. The antidiabetics have varying effectiveness and with several side effects, ${ }^{5}$ whilst the 
hypertension treatment has been revolutionised by the introduction of many new classes; particularly, the calcium channel blockers (CCB), the angiotensin converting enzyme inhibitors (ACEI), the angiotensin receptor blockers also called (also called T-blockers), the diuretics and other drugs that are cost-effective safe. In Morocco, as in many other African countries, there is a paucity of use of antihypertensives and antidiabetics amongst the general population. This study aimed to contribute to developing a picture of the pharmacoepidemiological profile of antihypertensives and antidiabetics in Morocco for academic purposes.

\section{Methods Location}

This study was conducted in the province of Figuig in south-eastern Morocco. This province has a semi-arid climate with an area of $55990 \mathrm{~km}^{2}$, which represents $7.92 \%{ }^{6}$ of the Moroccan land mass, and is suitable for the agricultural livestock. ${ }^{7}$ According to the national census of the Moroccan population (2014), the total population of the province included 138325 inhabitants defining a density of 2.5 inhabitants $/ \mathrm{km}^{2}$ and $50 \%$ of the population living in rural areas. ${ }^{8}$ The global multi-dimensional poverty is at $13.1 \%$ whilst the rates of illiteracy and health privation were $52.8 \%$ and $9.6 \%$ respectively (2014). ${ }^{9}$ The official number of diabetic subjects recorded in the prefecture was 1316 subjects (788 women vs. 528 men) and 1076 hypertensive subjects (699 women vs. 377 men) (2016).

\section{Study design}

This is a cross-sectional study funded by the Ministry of Health through a partnership with Ibn Tofail University. We followed the annual programme of medical caravans and medical visits to investigate diabetic and hypertensive subjects across different geographic locations of the prefecture. Patients aged 30 years and more who came for consultations were selected randomly and were screened using a semi-structured questionnaire, and their anthropometric and biological parameters were measured. Patients with advanced symptoms were transferred to specialised consultations, and those with medical prescriptions were directed to the pharmacy to be treated. Pregnant women, recently diagnosed patients (less than 1 year) and subjects not able to communicate were not included in this work.

\section{Statistical analysis}

Data were transferred from the questionnaire paper into an electronic database. We performed the analysis using EpiInfo software, and after adjustment we used univariate descriptive statistics to express the characteristics of patients. Our results were expressed as mean $( \pm)$, standard deviation (s.d.), percentage (\%) or as number of cases $(n)$. We used the $t$-test to compare means and the $\chi^{2}$-test to compare proportion.

\section{Ethical consideration}

The study received ethical clearance from Ibn Tofail University and Ministry of Health of Morocco on 01 December 2016 (ethical clearance number: P1-12/16-LGB$\mathrm{MH})$. A contract and partnership were formed between Ibn Tofail University and the Ministry of Health to support and authorise this study following the ethical standards. All procedures in this study were in accordance with the ethical standards of the National Committee and the 1964 Helsinki Declarations. Participants were asked to share their information for scientific research purposes; those who refused were screened for their medication and their data were not included. Participants were assured regarding the confidentiality of their information. The special terminologies and words have been accepted to express medical meanings to ensure the effectiveness of the communication, because most subjects were not well-versed with the local language. Considering the local traditions, wives were interviewed and screened in the presence of their husbands.

\section{Results}

Our sample comprises 244 subjects with a mean age of 60.64 (s.d. \pm 12.90 ) years which form a population of diabetic subjects $(56.96 \% ; n=139)$ and hypertensive subjects $(43.03 \%$; $n=105)$ and were predominantly women $(58.15 \% ; n=142)$ $(p<0.03)$ selected randomly from various geographic locations, rural areas (59.01\%) and urban areas (40.98\%) in one prefecture. Table 1 summarises the main characteristics of the population.

\section{Pharmacotherapy antihypertensive and antidiabetics}

Most subjects had a medical insurance (92.62\%) and low educational level $(24.18 \%)$. Only $7.78 \%$ of all subjects were not following any pharmacological treatment for their chronic conditions. The distribution of pharmacological treatments over patients is shown in Figure 1.

Regarding their therapeutic conception and after adjustments, $60.24 \%$ of all patients were undergoing monotherapy (hypertension $29.91 \%(n=73)$ and diabetes $30.32 \%(n=74)$ ) and the rest used combinations therapies for single or multiple chronic conditions. Several compounds from various pharmacological classes were employed to treat these conditions. Thus, for diabetes, the main compounds used in monotherapy are the biguanides (26.92\%), insulin therapy (20.0\%) and sulfonylureas (10.0\%). Patients under bi-therapies (18.46\%) were divided into two major associations: biguanides with insulin (13.07\%) and biguanides with sulfonylureas $(5.38 \%)$. The rest $(24.61 \%)$ were under combinations of antidiabetics, antihypertensive medication, because they were affected simultaneously by diabetes and hypertension, with cholesterol lowering (statins) or with antithrombotic.

Hypertensive subjects use CCB (27.36\%), ACEI (21.05\%), angiotensin T-blockers (16.84\%), diuretics $(7.36 \%)$ and b-adrenergic receptors blockers ( $\beta$-blockers) (3.15\%) as part of 
TABLE 1: Characteristics of the population.

\begin{tabular}{|c|c|c|c|c|c|c|}
\hline \multirow[t]{2}{*}{ Characteristics } & \multicolumn{2}{|c|}{ Diabetics } & \multicolumn{2}{|c|}{ Hypertensive } & \multicolumn{2}{|c|}{ Total } \\
\hline & $\%$ & $n$ & $\%$ & $n$ & $\%$ & $n$ \\
\hline Number & 56.96 & 139 & 43.09 & 105 & 100 & 244 \\
\hline Mean age (years) & $57.16 \pm 12.47$ & - & $65.26 \pm 12.04$ & & $60.64 \pm 12.90$ & \\
\hline Men & 23.77 & 58 & 18.03 & 44 & 41.80 & 102 \\
\hline Women & 33.19 & 81 & 25.0 & 61 & 58.19 & 142 \\
\hline Disease duration & $7.3 \pm 5.5$ & & $6.33 \pm 4.45$ & & $6.82 \pm 5.02$ & \\
\hline Education & 17.62 & 43 & 6.55 & 16 & 24.18 & 59 \\
\hline Medical insurance & 92.08 & & 93.33 & & 92.62 & \\
\hline Other chronic condition (epilepsy, asthma, rheumatism, etc.) & 5.75 & - & 8.57 & & 6.96 & \\
\hline No treatment & 3.68 & 9 & 4.09 & 10 & 7.78 & 19 \\
\hline
\end{tabular}

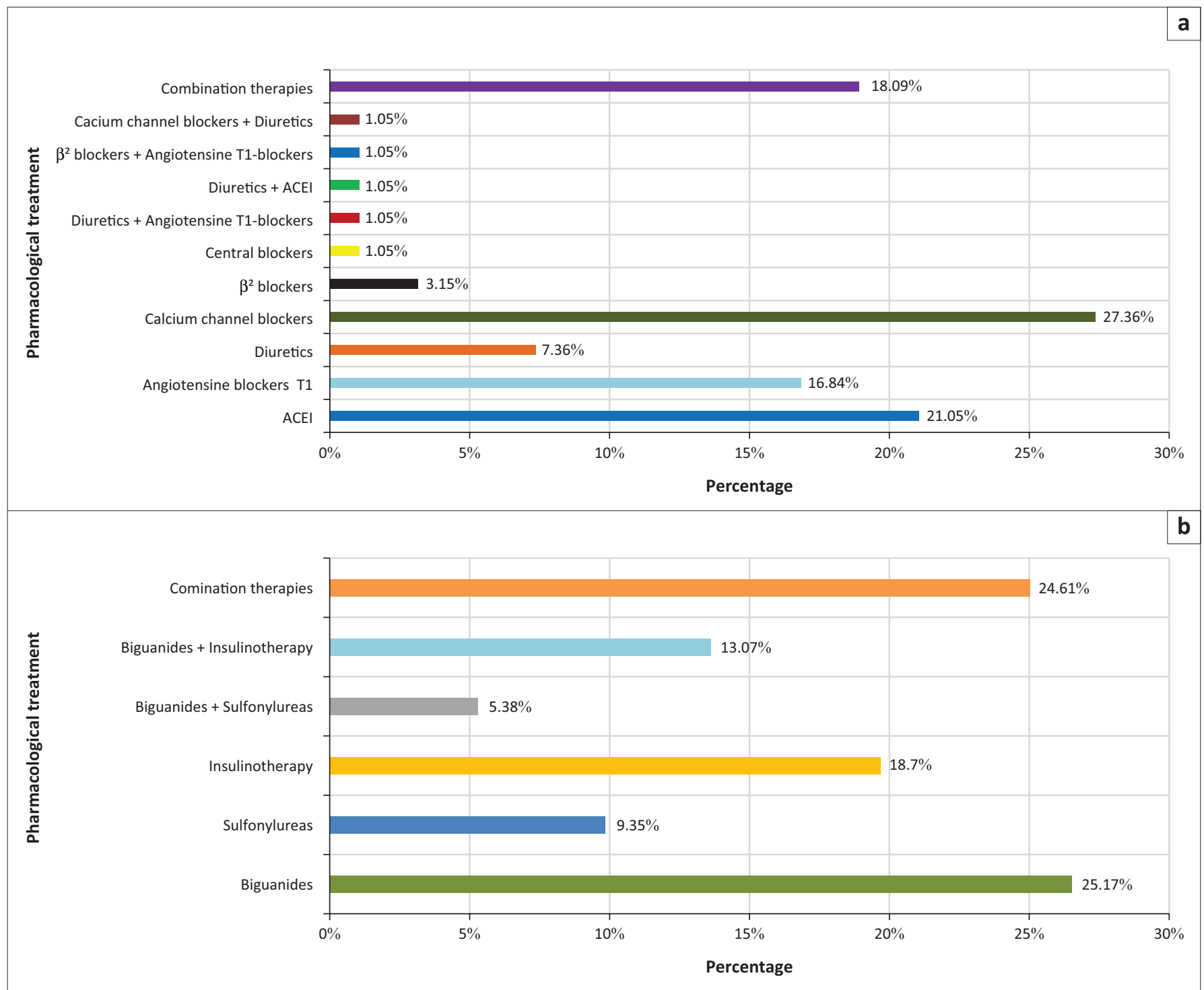

ACEI, angiotensin converting enzyme inhibitors.

FIGURE 1: Distribution of therapies using antihypertensive and antidiabetics over patients (a) Pharmacological treatment of hypertensive subjects; (b) Pharmacological treatment of diabetic subjects.

the monotherapy treatment. The bi-therapy antihypertensive (4.21\%) uses combinations of diuretics with ACEI, $\beta$-blockers with T-blockers, $\mathrm{CCB}$ with diuretics and diuretics with T-blockers. The rest $(20.03 \%)$ uses combinations of antihypertensive, cholesterol lowering (statins), antithrombotic and antiarrhythmic drugs. The general prevalence of polypharmacy (drugs $\geq 5$ ) is $1.22 \%$; all of them were diabetics $(2.15 \%)$ using combination therapies of antidiabetics, antihypertensives, cholesterol lowering drugs and antithrombotics.

Combination therapies include various therapies, such as antidiabetics, antihypertensive, cholesterol lowering, antithrombotic and antiarrhythmic drugs. 
TABLE 2: Description of side effects reported in the survey.

\begin{tabular}{|c|c|c|c|c|c|c|}
\hline \multirow[t]{2}{*}{$\begin{array}{l}\text { Side-effects reporting } \\
\text { frequencies }\end{array}$} & \multicolumn{2}{|c|}{$\begin{array}{l}\text { Hypertension } \\
\text { group }\end{array}$} & \multicolumn{2}{|c|}{$\begin{array}{l}\text { Diabetes } \\
\text { group }\end{array}$} & \multicolumn{2}{|c|}{$\begin{array}{c}\text { Total } \\
\text { sample }\end{array}$} \\
\hline & $\%$ & $n$ & $\%$ & $n$ & $\%$ & $n$ \\
\hline Bradycardia & 1.05 & 1 & $0 \%$ & - & 0.44 & 1 \\
\hline $\begin{array}{l}\text { Stomach ache, nausea, } \\
\text { vomiting, abdominal } \\
\text { discomfort }\end{array}$ & 11.57 & 11 & 10.76 & 14 & 11.11 & 25 \\
\hline $\begin{array}{l}\text { Dizziness, headache, } \\
\text { tinnitus }\end{array}$ & 10.52 & 10 & 3.84 & 5 & 6.66 & 15 \\
\hline $\begin{array}{l}\text { Asthenia, feeling sick, } \\
\text { feeling of faintness }\end{array}$ & 5.26 & 5 & 5.38 & 7 & 5.33 & 12 \\
\hline Coughing & 1.05 & 1 & 0 & - & 0.44 & 1 \\
\hline $\begin{array}{l}\text { Delivery product's } \\
\text { injection point }\end{array}$ & 0 & - & 3.07 & 4 & 1.77 & 4 \\
\hline
\end{tabular}

\section{Pharmacovigilance}

Almost $23.00 \%$ of all subjects have experienced negative side effects; this is distributed into $12.43 \%$ of diabetics and $10.66 \%$ of hypertensive patients. These adverse reactions were reported (90.38\%) to health professionals and $23.52 \%$ of them had their treatments interrupted temporarily or changed. Interestingly, men report the side effects to health professionals more than women $(100 \%$ vs. $86.11 \%)$ and interrupt the treatment or try to change their treatment more compared to women $(33.33 \%$ vs. $19.44 \%)(p<0.02)$.

Gastrointestinal problems were the most adverse reactions reported by $11.11 \%$ of subjects $(11.57 \%$ in the hypertension group and $10.57 \%$ in the diabetes group). The second most reported side effects include headache, dizziness and tinnitus $(6.66 \%)$ which are observed more frequently amongst the hypertension group than the diabetes group $(10.52 \%$ vs. $3.84 \%$ ). Side effects such as asthenia, feeling sick and a feeling of faintness were reported with a frequency of $5.33 \%$. Table 2 describes the main side effects reported in the survey.

\section{Discussion}

This is the first observational pharmacoepidemiological investigation of antidiabetics and antihypertensives utilisation in one prefecture in Morocco.

In Morocco, since 2011, the generalisation of the basic healthcare insurance, especially amongst needy populations, has been improving the healthcare access, chiefly the pharmacological treatment. ${ }^{10}$ Affected by the expansion of the national pharmaceutical market, the consumption of these drugs has increased drastically in the last decades, encouraged by the generic penetration and advancement of the therapeutic innovations in Morocco.

In terms of antidiabetics, our findings pointed out the widespread use of the biguanides, both in monotherapy and in association with various antidiabetic agents, and defined the same epidemiological pattern in other developing African countries. ${ }^{11,12,13}$ The national pharmaceutical market of antidiabetics progressed from ranging over six specialties (1991) to 16 specialties (2005) translating the huge demands for these agents, evolving from 1.9 to $14 \mathrm{DDD} / 1000$ inhabitants/day (DDD = defined daily dose) from 1997 to 2014. ${ }^{14}$ Analyses show that the national consumption of sulfonylureas and metformin have increased by four and 10 times respectively from 1997 to 2004 . Our results show that $21.37 \%$ of diabetic patients experienced discomfort with their pharmacological treatment. A prospective study ${ }^{15}$ of oral antidiabetics amongst Moroccan diabetic patients indicated that $50 \%$ of those patients experienced adverse reactions, mostly related to metformin (95\%) and sometimes did require the interruption of treatment, whilst sulfonylureas were mainly linked to hypoglycaemia as their side effect $(0.5 \%)$.

Most of the antidiabetics described in our survey are available in public health facilities as part of the national health policy for managing chronic diseases (2012). ${ }^{10}$ The class of biguanides is generally well-tolerated compared to insulin, is inexpensive, acts by decreasing the insulin resistance, inhibits hepatic gluconeogenesis and opposes the action of glucagon. Their preventive actions on the cardiovascular system were confirmed in 53 observational and experimental studies ${ }^{16}$ (Hazard ration HR 0.78, 95\%, CI 0.73-0.83, $p<0.00001$ ) as compared to the insulin group. Their main adverse reactions include nausea, abdominal discomfort and some diarrhoea. ${ }^{17}$ Generally, metformin has to be taken with meals in an increasing dose as tolerated. A retrospective cohort study ${ }^{16}$ conducted in England and Wales has linked insulin with an increased risk of composite non-fatal acute myocardial infraction, which causes death and non-fatal stroke (HR 2.6, $95 \%$, CI 1.9-3.4). The association of biguanides with insulin ${ }^{16}$ was linked to gastroduodenal discomfort, weight loss and hypoglycaemia. The class of sulfonylureas ${ }^{17}$ acts as insulin secretagogues, and as $\beta$-cell pancreatic dysfunction progresses, they become less effective. They are inexpensive, but their main adverse reaction includes symptomatic episodes of hypoglycaemia.

In Morocco, the use of antihypertensive drugs increased from 0.08 to 10.65 DDD/1000 inhabitants/day between 1991 and 2010 with a dominance of CCB drugs (82.09\%) followed by ACEI drugs (48.29\%). ${ }^{18}$

Our findings reveal that drugs acting on the reninangiotensin aldosterone system (RAAS) are widely used in monotherapy (37.89\%) represented by two major pharmacological classes: ACEI and T-blockers. Generally, they are considered as the first line and are quite effective in the management of hypertension. ${ }^{19}$ The most important adverse reaction ${ }^{20}$ in this group is represented by dry cough because of increase in bradykinin concentration which may constitute an indication to switch from ACEI to T-blockers. Other side effects include angioedema, hyperkalaemia and diarrhoea. ${ }^{21}$ When combined with $\beta$-blockers, they have additive cardio-protective actions with less antihypertensive action. ${ }^{22}$ The second major pharmacological class was represented by CCB represented with its two subgroups: the Phenylalkylamine (verapamil) and dihydropyridine 
(amlodipine). ${ }^{23}$ Their pharmacological antihypertensive action resulting in vasodilatation is considered more effective than the ACEI and $\beta$-blockers, especially in the African population. ${ }^{24}$ Their adverse reactions are dose dependent, because of their vasodilatation actions, and essentially include gastrointestinal problems (constipation associated with Verapamil in 13\%), headache, dizziness, lightheadedness, flushing, hypotension and peripheral oedema $(10 \%-20 \%$ of all patients) more commonly found in women and probably because of an increased capillary pressure and for which the association with diuretics may not reveal this oedema, whilst the association with ACEI or T-blockers may reduce or prevent it. ${ }^{23,25}$ The results of 22 clinical trials ${ }^{24}$ show lower incidence of diabetes compared to diuretics and $\beta$-blockers but greater than ACEI and T-blockers. Their association with diuretics is acceptable considering that they excrete sodium preventing the volume depletion that occurs with diuretics and their help in reduction of cardiovascular risks. ${ }^{26}$ The third antihypertensive class represented by the diuretics contains three major groups of compounds depending on their pharmacological actions: the thiazides (hydrochlorothiazide and indapamide), the loop diuretics (furosemide) and the potassium spearing diuretics (spironolactone). ${ }^{27}$ The main adverse reactions of diuretics include headaches, dizziness, increased blood glucose, gout, diarrhoea, kidney failure and irregular heartbeat. They reduce the intravascular volume and activate the Renin Angiotensin Aldosterone system (RAAS) leading to vasoconstriction and the retention of sodium and water. ${ }^{28}$ Therefore, the association with an ACEI or T-blockers attenuates this irregularity and ameliorates the hypokalaemia with an increasing risk of hyperkalaemia. ${ }^{29}$

The $\beta$-blockers are used as a second line of hypertension management, especially amongst patients who survived an acute myocardial infraction, heart failure and atrial fibrillation by reducing the heart's rhythm. When compared to ACEI, T-blockers and CCB, the $\beta$-blockers have a reduced action on hypertension. $^{30,31}$ Their adverse reactions, which can be explained by understanding their molecular mechanism and competitive antagonist action on c-adrenoceptors, include interference with heart rate, hypotension, hypoglycaemia, abdominal pain, nausea, vomiting, constipation, dizziness, depression and many others. ${ }^{32}$

In this survey, $6.9 \%$ of all participants have associated chronic conditions, such as asthma, rheumatism, psychological disorder and epilepsy which increase the complexity therapeutic not only for the subjects but also for health professionals as it increases the risk of drug-drug interactions. Our findings show an adjusted prevalence of polypharmacy ${ }^{33}$ in $1.22 \%$ observed diabetic subjects. We consider two major factors that determine the success of combination therapies:

1. Tolerability: Usually, antidiabetic and antihypertensive drugs have pharmacological actions and adverse reactions that are dose dependent, hence, low-dose initiations are always preferable.
2. Adherence: The subject's ability to respect the therapeutic guidelines, particularly, with multiple drugs that have to be taken at the same time and/or in increasing number of doses per day and amongst illiterate subjects which may affect patients' compliance negatively, who will try to change or interrupt its treatment. We found that $23.53 \%$ of subjects who did experience adverse reactions have interrupted temporarily or tried to change it by themselves without any medical consultations which exposed them to negative clinical outcomes and complications. Morocco has an advanced system of pharmacovigilance compared with other Arabic countries and full membership with the World Health Organization (WHO) Collaborating Center for International Drug Monitoring (WHO-Uppsala Monitoring Center). The system has a centric structure based on the National Center of Pharmacovigilance (launched in 1989) and the National Pharmacovigilance Committee. ${ }^{34}$ Spontaneous reports of adverse reactions are made by health professionals essentially depending on their initiative and motivation. In our investigation, the vast majority of adverse reactions were reported to health professionals who probably were not sufficiently trained to deal with these reactions or take them seriously.

\section{Limitation and perspectives}

Our sample was representative of registered patients in the prefecture (nearly 10\%); extrapolation to the general population should consider the ethnic diversity (Arabs and Amazigh) and the socioeconomic variations that characterise the Moroccan population and which may affect the lifestyles.

Further investigations are required to define new strategies of side effects of medication in long-term use.

\section{Conclusion}

Managing diabetes and hypertension still pose a lot of public health challenges and requires more focus and interest, especially amongst the illiterate population in remote areas. The management measure should include the introduction of new innovative measures, systems of follow-up and adverse reactions management, at the individual, regional and national levels.

\section{Acknowledgements}

The authors thank Dr Abdallah Ouadie, the head of local authority of the Ministry of Health, and Mr Kabori Mohamed, prefectural economist in health authority in the prefecture of Figuig. The authors thank all the drivers affiliated to the prefectural hospital in Bouarfa and all health professionals in the prefecture of Figuig.

\section{Competing interests}

The authors declare that no competing interests exist. 


\section{Authors' contributions}

E.R., A.S., H.H. and M.A. were involved in study concept and design. R. E. was involved with the acquisition of data. The data collected were analysed and interpreted by all the authors, and everyone was involved in the critical revision of the results thus obtained. This study was supervised by A.S.

\section{Funding information}

This research received funds from the Ministry of Health of Morocco.

\section{Data availability statement}

The data sets generated during and/or analysed during the current study are available from the corresponding author on reasonable request.

\section{Disclaimer}

The views and opinions expressed in this article are those of the authors and do not necessarily reflect the official policy or position of any affiliated agency of the authors.

\section{References}

1. WHO. Global status report on noncommunicable diseases. Geneva: World Health Organization; 2014.

2. Bertram MY, Sweeny K, Lauer JA, et al. Investing in non-communicable diseases: An estimation of the return on investment for prevention and treatment services. Lancet. 2018;391(10134):2071-2078. https://doi.org/10.1016/S01406736(18)30665-2

3. Diab M, Barhoosh HA, Daoudi B, et al. Prevention and screening recommendations in type 2 diabetes: Review and critical appraisal of clinical practice guidelines. Prim Care Diabetes. 2018;13(3):197-203. https://doi. org/10.1016/j.pcd.2018.11.014

4. Flack JM, Adekola B. Temporary removal: Blood pressure and the new ACC/AHA hypertension guidelines. Trends Cardiovas Med. 2019;29(4):191-248.

5. Pareek M, Bhatt DL. Oral antidiabetic agents and cardiovascular outcomes. Curr Probl Cardiol. 2018;43(3):111-126. https://doi.org/10.1016/j.cpcardiol.2017. 07.003

6. Kingdom of Morocco. Ministry of Interior Province of Figuig. Monograph of the prefecture of Figuig. Morocco (French). 2005 [cited 2019 May 19]. Availible from http://www.oriental.ma/upload/MoDUle_1/File_1_99.pdf

7. Elyamani R, Soulaymani A, Serheir Z. Epidemiology of scorpion envenoming in the prefecture of figuig, Morocco. Int J Med Toxicol Forensic Med. 2019;9(1):17-24 https://doi.org/10.22037/ijmtfm.v9i1\%20(Winter).23632

8. Kingdom of Morocco. Ministry of interior. General direction for local authorities General monograph of the Eastern of morocco (French). [homepage on the Internet]. 2015. [cited 2019 May 20]. Available from: http://www.pncl.gov.ma/fr/ Publication/Statistique/Pages/Monographie-des-r\%C3\%A9gions-.aspx

9. Kingdom of Morocco. High commissioner for the plan. Regional management of the Eastern. Key indicators for the province of figuig. [homepage on the Internet]. General census in Morocco; 2016 [cited 2019 May 22]. Available from: http:// www.hcp.ma/region-oriental/docs/RGPH2014INDICATEURS/Indic2014_FIGUIG. pdf
10. Kingdom of Morocco Ministry of Health. National health strategy by sector: 2012-2016. [homepage on the Internet]. [cited 2019 May 24]. Available from: https://www.sante.gov.ma/Pages/Dossiers.aspx

11. Ekou F. CA-036: Pharmacoépidémiologie du diabète: Usage des antidiabétiques à l'Institut National de Santé Publique de Côte d'Ivoire (résultats préliminaires). Diabetes Metab. 2016;42(1):A44-A45. https://doi.org/10.1016/S1262-3636(16) 30168-9

12. Ntyonga-Pono MP. L'observance du traitement antidiabétique chez les patients diabétiques au Gabon: Données préliminaires. Med Maladies Metabol. 2015;9(2):198-202. https://doi.org/10.1016/S1957-2557(15)30043-2

13. Tiéno $H$, Bouda $M$, Ouédraogo DD, Traoré R, Ouédraogo $C$, Drabo YJ. Observance du traitement antidiabétique dans un pays en développement: Le cas du Burkina Faso (Afrique subsaharienne). Med Maladies Metabol. 2010;4(2):207-211.

14. Mousannif S, Belaiche $A, C$ Cherrah $Y$, Ahid S. Trend in oral antidiabetics use among Moroccan patients. Value Health. 2016;19(3):A209. https://doi.org/10.1016/j. jval.2016.03.1270

15. Ajdi F, Khabbal Y, Amazian K. Profil épidémiologique des effets indésirables des antidiabétiques oraux. Rev Epidemiol Sante Publique. 2009;57(S1):6-7.

16. Schalliol LA, Pittman JA, Ray SD. Insulin and other hypoglycemic drugs. Side Eff Drugs Annu. 2018;40;537-546. https://doi.org/10.1016/bs.seda.2019.07.002

17. Varghese S. Noninsulin diabetes medications. Nurs Clin N Am. 2017;52(4):523537. https://doi.org/10.1016/j.cnur.2017.07.003

18. El Azizi GB, Ahid S, Ghannam I, Belaiche A, Hassar M, Cherrah Y. Les médicaments génériques et l'évolution de la consommation des antihypertenseurs au Maroc. Therapies. 2014;68(5):303-312. https://doi.org/10.2515/therapie/2013048

19. Charlton M, Thompson JP. Drugs acting on the heart: Antihypertensive drugs. Anaesth Intens Care Med. 2018;19(7):365-369. https://doi.org/10.1016/j.mpaic.2018.04.005

20. Bavishi C, Bangalore S, Messerli FH. Renin angiotensin aldosterone system inhibitors in hypertension: Is there evidence for benefit independent of blood pressure reduction? Prog Cardiovasc Dis. 2016;59(3):253-261. https://doi. org/10.1016/j.pcad.2016.10.002

21. Arumugam S, Sreedhar R, Thandavarayan RA, et al. Angiotensin receptor blockers: Focus on cardiac and renal injury. Trends Cardiovasc Med. 2016;26(3):221-228. https://doi.org/10.1016/j.tcm.2015.06.004

22. Luño J, Varas J, Ramos R, et al. The combination of beta blockers and renin angiotensin system blockers improves survival in incident hemodialysis patients: A propensity-matched study. Kidney Int Rep. 2017;2(4):665-675. https://doi. org/10.1016/j.ekir.2017.03.001

23. Chandra KS, Ramesh G. The fourth generation Calcium channel blocker: Cilnidipine. Indian Heart J. 2013;65(6):691-695. https://doi.org/10.1016/j.ihj.2013.11.001

24. Alun $\mathrm{H}$. Calcium channel blockers. In: Alun $\mathrm{H}$, editor. Hypertension: A companion to Braunwald's heart disease. 3rd ed. 2017; pp. 242-253.

25. Traylor K, Gurgle H, Brockbank J. Antihypertensive drugs. Side Eff Drugs Annu. 2018;40(1):263-267.

26. Rimoldi SF, Messerli FH, Chavez P, Stefanini GG, Scherrer U. Efficacy and safety of calcium channel blocker/diuretics combination therapy in hypertensive patients: A meta-analysis. J Clin Hypertens. 2015;17(3):193-199. https://doi.org/10.1111/ jch.12462

27. Vazir A, Sundaram V, Harper AR. Diuretic therapy. Encyclopedia of cardiovascular research and medicine. 2018; pp. 107-116.

28. Friedman-Jakubovics M, Fazylov R. Diuretics. Side Eff Drugs Annu. 2018;40(1): 269-278.

29. DeFilippis EM, Desai AS. Treatment of hyperkalemia in heart failure. Curr Heart Fail Rep. 2017;14(4):266-274. https://doi.org/10.1007/s11897-017-0341-0

30. Akbar S, Alorainy MS. The current status of beta blockers' use in the management of hypertension. Saudi Med J. 2014;35(11):1307-1317.

31. Yamamoto K. $\beta$-Blocker therapy in heart failure with preserved ejection fraction: Importance of dose and duration. J Cardiol. 2015;66(3):189-194. https://doi. org/10.1016/j.jjcc.2015.02.004

32. McHugh J, Pokhrel P, Barber K, Liu G. Beta-blockers in the management of cardiovascular diseases. Osteopathic Fam Phys. 2010;2(5):131-138.

33. Masnoon N, Shakib S, Kalisch-Ellett L, Caughey GE. What is polypharmacy? A systematic review of definitions. BMC Geriatr. 2017;17(230):1-10.

34. Alshammari TM, Mendi N, Alenzi KA, Alsowaida Y. Pharmacovigilance systems in Arab Countries: Overview of 22 Arab Countries. Drug Saf. 2019:42(7):1-20. https://doi.org/10.1007/s40264-019-00807-4 